\title{
qZS Inverter as Synchronverter in Small-Scale Micro-Grid
}

\author{
Janis Zakis ${ }^{1}$, Elena Makovenko², Hao Zeng ${ }^{3}$, Oleksandr Husev ${ }^{1,2}$, Lauri Kutt ${ }^{2}$ \\ ${ }^{1}$ Institute of Industrial Electronics and Electrical Engineering, Riga Technical University, \\ Azenes St. 12/1, LV-1048, Riga, Latvia \\ ${ }^{2}$ Department of Electrical Engineering, Tallinn University of Technology, \\ Ehitajate St. 5, 19086 Tallinn, Estonia \\ ${ }^{3}$ University of Wisconsin-Madison, Wisconsin Electric Machines and Power Electronics Consortium \\ (WEMPEC), \\ Madison, WI 53706 USA \\ oleksandr.husev@ieee.org
}

\begin{abstract}
Focus is on the case study of a synchronveter model use in the qZS inverter working in an islanding operation mode. Main tasks and control principles of a sychronverter in the microgrid are explained.

Theoretical assumptions are tested and verified with Psim simulation model with different types and powers of microinverter loads. General waveforms are presented and discussed. Also, the effectiveness of synchronverter implementation is verified by means of grid regulation capability.

Additionally, we address the most challenging tasks for further developments and improvements of the qZS inverter based synchronverter in microgrids.
\end{abstract}

Index Terms-DC-AC power converters; Voltage-source converters; Static power converters; Power quality.

\section{INTRODUCTION}

Introduction of Grid Connected Distributed Power Generation Sources (DEGSs) in modern power systems is increasing [1]. This makes the power electronics interface converter a key element for adjusting power parameters (voltage level, frequency) before injecting it in the grid. For many years, keeping injected power parameters under established standards was not considered critical, because large synchronous generators (typically in hydro power plants or combined heat and power stations) in the system were able to keep stability and constant parameters. Such systems are called centralized.

In recent years, power systems have become decentralized because the number of DEGS in the supply network is dramatically growing and synchronous generator cannot keep the stability of the system and parameters at rated values any more. As a result, new tasks and challenges have been set to grid connected inverters. Inverters should

Manuscript received 22 October, 2017; accepted 26 January, 2018.

This research was supported by Latvian National Research Program 'LATENERGI' and Latvian Council of Science (grant no. 673/2014) Ukrainian partner work is supported by grants (No. 0116U004695 and No. 0116U006960) from the Ukrainian Ministry of Education and Science. Estonian partner work is supported by Estonian government (PUT1443 and PSG142). play a more serious role in the power system by keeping constant and improving grid parameters and increasing supply reliability if a synchronous generator failed. The synchronverter that mimics a synchronous machine and inherits its properties in the system has been proposed for solution. The idea of the synchronverter and the implementation of the mathematical model of a synchronous machine in the conventional inverter was proposed in [2] [13].

DEGSs usually do not provide constant output voltage because primary sources like sun, wind, etc. are changing. A common approach of introducing an intermediate step-up dc-dc converter can be used here to provide rated dc bus voltage. Recent high interest among researchers has resulted in impedance source based inverters in various applications due to their unique properties (shoot-through immunity, high input voltage gain etc.) [14]-[16].

In addition, there is a difference in controlling an inverter in the grid connected mode and in the islanding mode. In the first case, the output controller is a current controller, i.e. PR; PID; Deadbeat; Predictive; Fuzzy Logic, hysteresis. While in the islanding mode, an inverter starts operating as a voltage source, thus the output controller should be a voltage controller. In both modes, the system for synchronization such as phase-locked loop (PLL) should be applied; in the grid-connected mode, to synchronize produced current with grid voltage and in the islanding mode, to generate the desired frequency. In [17] the digital hysteresis controller with PI controller and state feedback was proposed. In [18]-[20] a PI controller was selected to control the output voltage since it showed good performance in $d q$ reference frame. The good dynamic behaviour of the whole system during the transient time from the islanding mode to the grid-connected mode was shown in all those papers.

Our aim is to combine the benefits of a synchronverter with an impedance source and more particular quasi-Zsource (qZS) network [21], [22] in the input side. This solution may provide a wide input voltage regulation range along with short circuit immunity, which means enhanced 
reliability.

\section{CASE STUdy System DESCRIPTION}

This section describes the case study system. Fig. 1 shows the schematic diagram of the micro-grid cell that is disconnected from the central grid. The single-phase quaziZ Source Inverter (qZSI) in the islanding mode operates as a synchronous generator, which sets frequency and voltage based on the load demand. The microinverter can be connected in parallel to the synchronverter with a different load. It operates in the normal grid-connected mode. The Photovoltaic (PV) string can be considered a power source. In this case, the battery is connected to the dc-link voltage and allows expanding the capabilities of the whole system by charging and discharging in power production at any time.

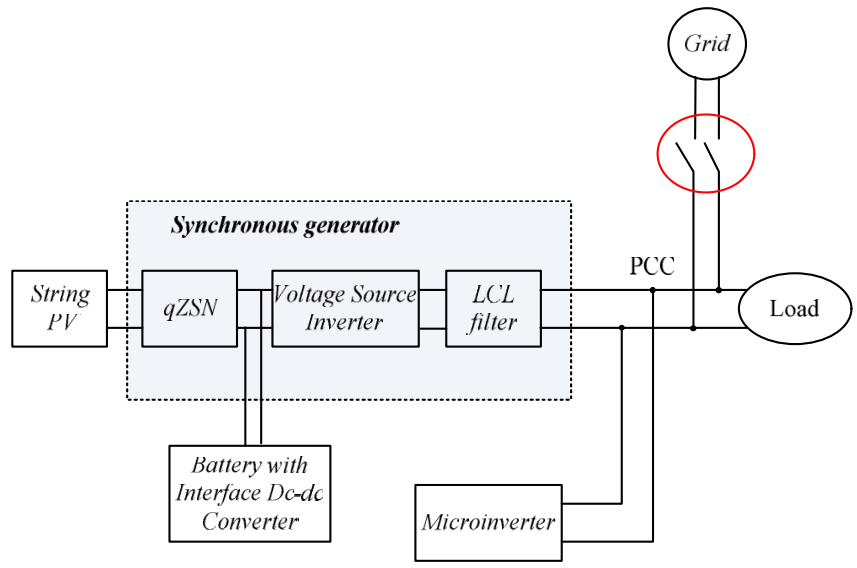

Fig. 1. Schematic diagram of the case study micro-grid.

In case the synchronverter can mimic the behaviour of the synchronous generator, the implementation of the droop control in the microinverter becomes reasonable. The reason is that several microinverters along with the synchronverter can maintain grid balanced and stable.

In this particular case, a scaled small power system is under consideration. A microinverter means an inverter that has much lower power than the synchronverter. Table I shows the parameters of this particular system.

TABLE I. SYSTEM PARAMETERS.

\begin{tabular}{|c|c|}
\hline Parameter & Value \\
\hline Input voltage range of synchronverter & $220 \mathrm{~V}-400 \mathrm{~V}$ \\
\hline Input voltage of microinverter & $400 \mathrm{~V}$ \\
\hline Refernce power of microinverter & $325 \mathrm{VA}$ \\
\hline Nominal power of synchronverter & $1 \mathrm{KVA}-10 \mathrm{KVA}$ \\
\hline LCL filter of synchronverter & $560 \mathrm{uH} ; 0.47 \mathrm{uF} ; 200 \mathrm{uH}$ \\
\hline qZS networks parameters & $0.45 \mathrm{mH} ; 1 \mathrm{mF}$ \\
\hline LCL filter of microinverter & $2.2 \mathrm{mH} ; 0.47 \mathrm{mF}, 1 \mathrm{mH}$ \\
\hline
\end{tabular}

\section{CONTROL SYSTEM STRUCTURE AND DESCRIPTION OF IMPLEMENTATION}

Figure 2 presents a general circuit diagram of the proposed system which consists of a qZSI and an LCL filter with passive load. $I_{a}$ is the output current of the qZS inverter, $I_{g}$ is grid current; in which case it is Voltage Source Generator (VSG) current.

Figure 3(a) and Fig. 3(b) present second order generalized integrators used to extract real $(\alpha)$ and imaginary $(\beta)$ components to obtain single phase instantaneous active and reactive power. $v_{g}$ is the grid voltage. Steady state $v_{\mathrm{g}_{-} \alpha}$ is regulated to be the same with $v_{\mathrm{g}}$ because of the negative feedback.

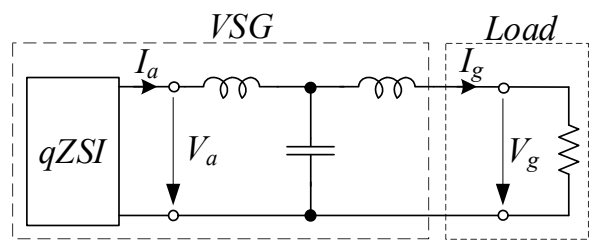

Fig. 2. General circuit diagram of the system.

Steady state $v_{g \beta}$ is regulated to be $90^{\circ}$ phase shifted compared to $v_{g_{-} \alpha}$. So $v_{g_{-} \alpha}$ and $v_{g \_}$are real and imaginary axis power generated by SOGI. $\omega_{0}$ is used to determine the resonant frequency.

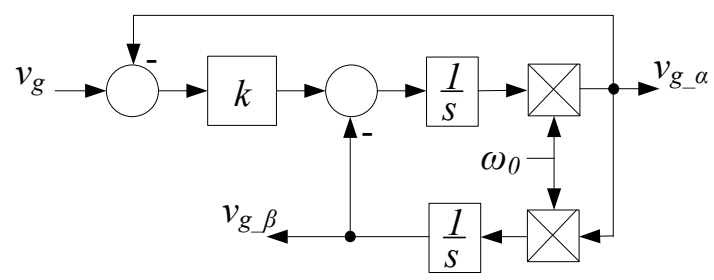

(a)

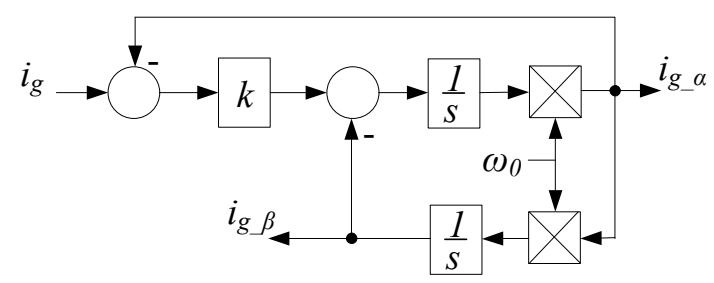

(b)

Fig. 3. Second order generalized integrator.

Based on the generated real and complex components as discussed above, single-phase instantaneous power can be calculated by (1) and (2).

Power references $p_{0}^{*}$ and $q_{0}^{*}$ are obtained from the nominal power:

$$
\begin{aligned}
& d=\frac{1}{2}\left(v_{g \alpha} \times i_{g \alpha}+v_{g \beta} \times i_{g \beta}\right), \\
& q=\frac{1}{2}\left(v_{g \beta} \times i_{g \alpha}+v_{g \alpha} \times i_{g \beta}\right),
\end{aligned}
$$

where $v_{g \alpha}-\alpha$ component of grid voltage, $v_{g \beta}-\beta$ component of grid voltage, $i_{g \alpha}-\alpha$ component of grid current, $i_{g \beta}-\beta$ component of grid current. Second order mechanical model is used to emulate the feature of synchronous generator (Fig. 4), where $k_{i}, k_{p}$ - coefficients of PI regulator, $k_{f}$ - droop forming coefficient (dependent on real system).

The active inertia $J_{a}$ is used to emulate the physical inertia [23] of the rotor and active viscous damping coefficient $b_{a}$ is used to emulate the physical friction of the system. This mechanical emulation is the key benefit of a synchronous generator to build up a stiff and stable grid. Field winding emulation is not implemented since it does not provide the key feature that is mentioned above.

Figure 4 shows the reference voltage generation according to the f-p droop characteristics. It is used to enable primary frequency control such that a system can 
have frequency deviation and frequency can be stable with steady state error if the load has been changed. This frequency deviation is sensed by other grid connected inverters so that power should be balanced from those inverters.

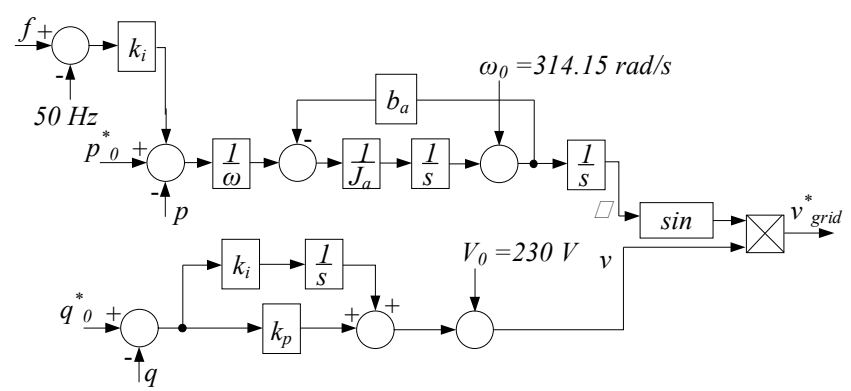

Fig. 4. State block diagram of reference voltage generation with f-P droop characteristics.

Table II summarizes the parameters of the selected f-P droop characteristics.

TABLE II. PARAMETERS OF SELECTED F-P DROOP CHARACTERISTICS

\begin{tabular}{|c|c|}
\hline Parameter & Value \\
\hline Integral term of PI regulator, $k_{i}$ & 0 \\
\hline Proportional term of PI regulator, $k_{p}$ & 0.001 \\
\hline $\begin{array}{c}\text { Droop forming coefficient (dependent on real } \\
\text { system), } k_{f}\end{array}$ & -20000 \\
\hline Active inertia, $J_{a}$ & 0.05 \\
\hline Active viscous damping coefficient, $b_{a}$ & 0 \\
\hline
\end{tabular}

\section{CONTROL System TuRning OF VSG IN THE SYNCHRONVERTER}

Since an inverter in the standalone mode starts to operate as VSG, it means that the output controller should control the quality of output voltage's form and frequency in the first place. Therefore, in order to control the main inverter that is a virtual synchronverter, a Proportional-Resonant (PR) controller was applied.

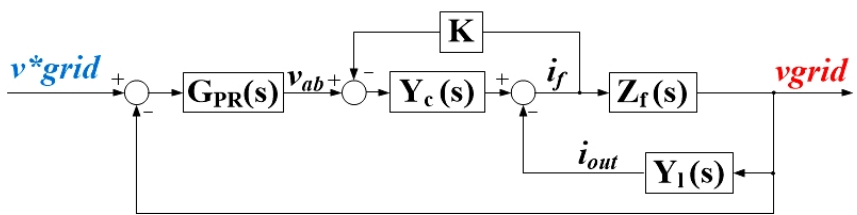

Fig. 5. Equivalent block diagram of VSG.

The transfer function of LCL filter can be expressed through $V o u t=V c$ and $V i n v$

$$
G_{L C L}(s)=\frac{V_{C}}{V_{i n v}}=\frac{Y_{i} Z_{c}}{1+Y_{i} Z_{c}+Z_{c} Y_{n}},
$$

where:

$$
\left\{\begin{array}{l}
Y_{i}(s)=\frac{1}{s L_{1}}, \\
Y_{n}(s)=\frac{1}{s L_{2}+R_{n}}, \\
Z_{c}(s)=\frac{1}{s C}+R_{d} .
\end{array}\right.
$$

The output PR controller's transfer function is

$$
G_{P R}(s)=K_{p r}+\frac{s K_{i r}}{s^{2}+\omega^{2}}
$$

where $K_{p r}$ is a proportional gain of the controller, selected equal to 1 and $K_{i r}$ is an integral gain of the resonant component selected equal to $600, \omega$ is fundamental angular frequency. The closed loop transfer function is expressed as follows

$$
G_{P R L C L}(s)=\frac{G_{P R} G_{L C L}}{1+G_{P R} G_{L C L}},
$$

Figure 6 presents the zero pole maps of the output transfer function under the condition of a time-varying load.

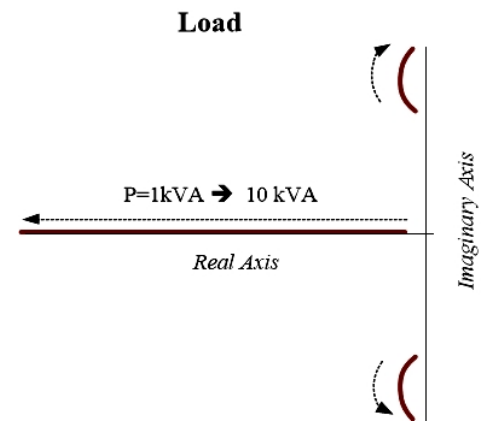

Fig. 6. Map of poles of the transfer function of the output PR controller and LCL filter.

Figure 6 shows that the selected parameters of the PR controller provide stable operation of the system in the whole range of predefined output power.

\section{Simulation Results}

First of all, the single-phase qZSI is simulated under timevaried load conditions (Fig. 7). The simulation results are shown in Fig. 8.

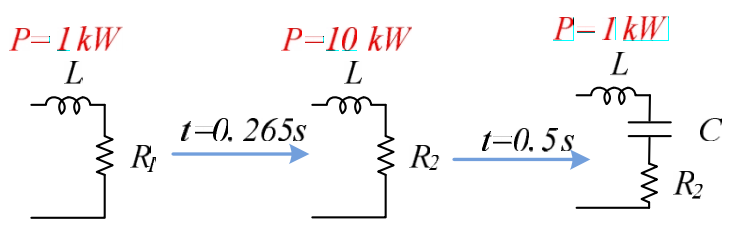

Fig. 7. Different types of load.

Figure 8 shows the load changing during simulation time, the following parameters were selected for simulation: $R 1=$ 92.7 Ohm, $R 2=10.6 \mathrm{Ohm}, L=0.2 \mathrm{mH}, C=0.1 \mathrm{mF}$. Up to $0.265 \mathrm{~s}-t_{1}$ the inverter's output power was $1 \mathrm{~kW}$, the load was active-inductive. At $0.265 \mathrm{~s}$, the demand of power by load was changed to $10 \mathrm{~kW}-t_{2}$. At time $0.5 \mathrm{~s}$, the load demand was changed again up to previous power demand and capacitive character of load $-t_{3}$ was added.

The simulation results show that inverter is able to produce the current and voltage of the required quality even when the load is varying with time. A problem is encountered with a non- active load when the inverter should be able to synchronize the produced voltage and current in order to reduce the reactive power production that affects the load and increases the energy cost. 

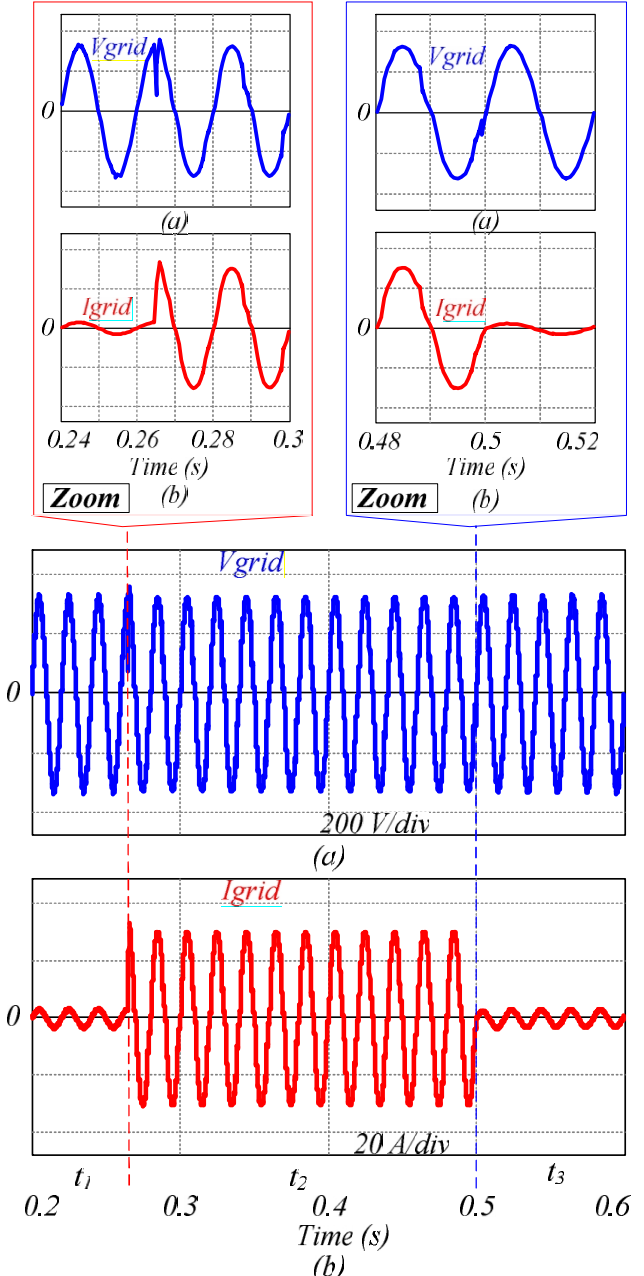

Fig. 8. The simulation results: a) grid voltage; b) grid current.

Figure 9 presents the simulation results under different load conditions and connection of microinverter. The load is only active till the moment of time $0.4 \mathrm{~s}$. At the time $0.4 \mathrm{~s}$, the microinverter is connecting to the whole system.

Figure 9 from top to bottom: grid voltage; grid current; output current of microinverter; output current of synchronous generator (qZS inverter). From the beginning, the synchronous generator is operating only.

At the moment of time $0.265 \mathrm{~s}$, the load demand is changed from $1 \mathrm{~kW}$ to $10 \mathrm{~kW}$. The transient time is very fast, the inverter is able to react fast to the load changing.

At the time $0.4 \mathrm{~s}$, the microinverter is connecting to the system and the produced current for the load is shared between the two inverters based on their power production capacity. The transient time in the microinverter is not so good, but it does not affect the total output current-grid current.

At the moment of time $0.5 \mathrm{~s}$, the load demand is changing the whole system from $10 \mathrm{~kW}$ to $1 \mathrm{~kW}$ to cope with this task very fast. The power is correctly shared between the inverters. At the same time, it can be seen that the transient process is complicated.

The next step was the verification of the function of the synchronverter. Figure 10 presents three loading steps implemented in the model. As the frequency curve shows, there is no load at the very beginning. The grid is not built up by qZSI since there is no reference voltage. In the next stage, voltage reference is applied, the load has nearly step change and power reference is also set to have the same step to balance the load.

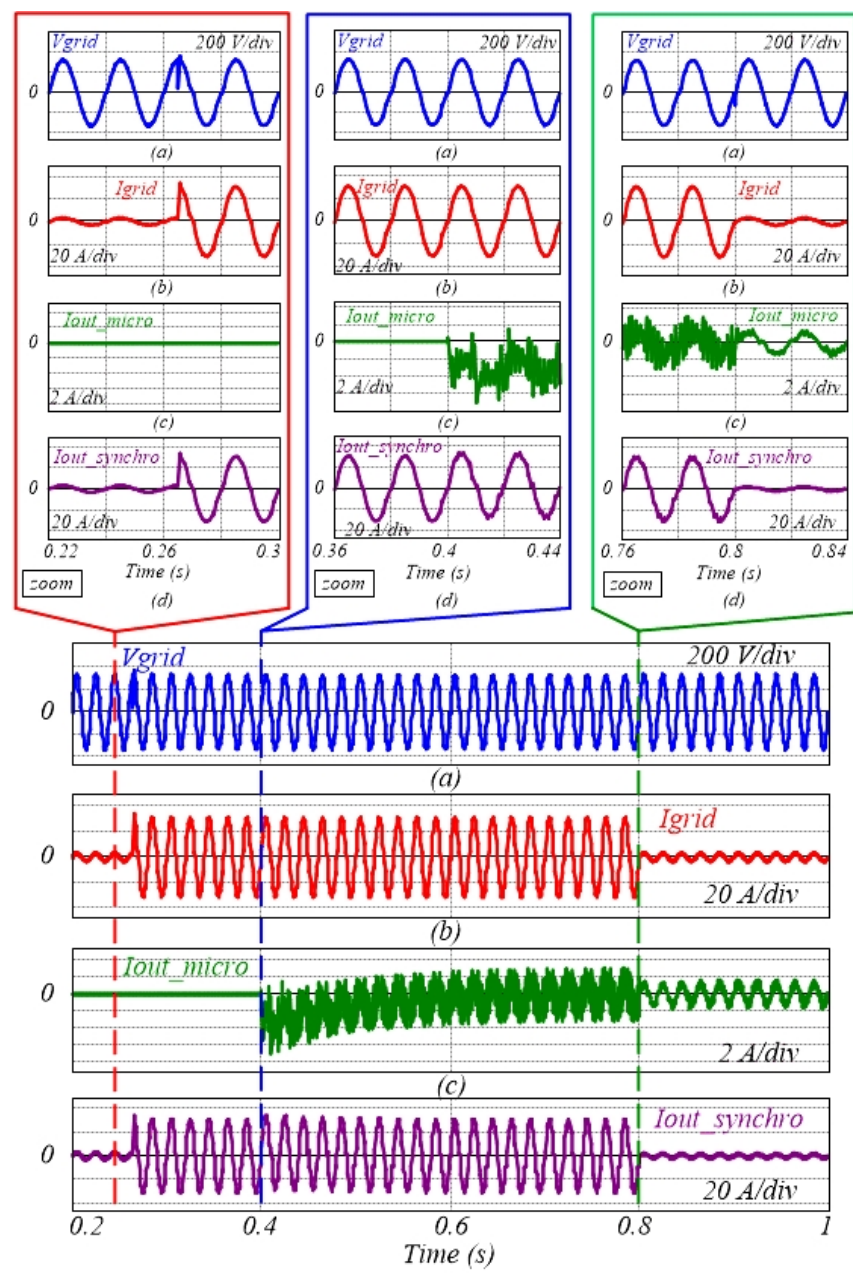

(d)

Fig. 9. Simulation results of the qZSN inverter with the microinverter in the islanding mode.
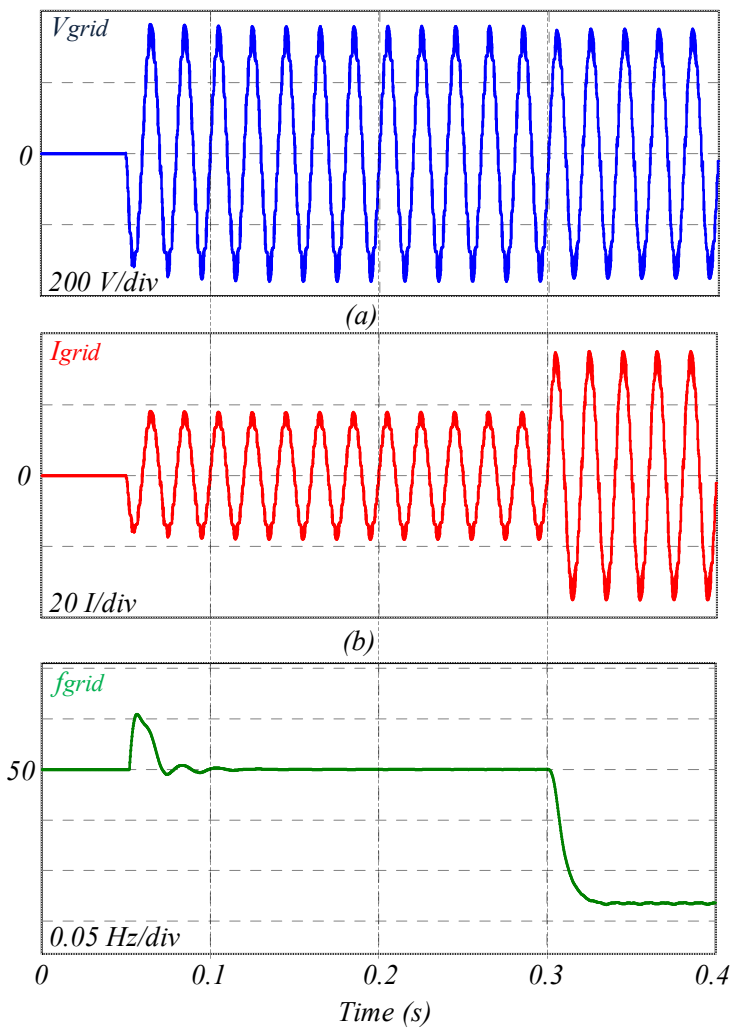

(c)

Fig. 10. Simulation waveforms of the proposed VSG. 
Although the frequency will be deviated during the transient, it goes back to $50 \mathrm{~Hz}$ due to the effect of the droop control. In the last stage, the load has been increased but the power reference is kept unchanged. Due to the effect of VSG, the frequency will be decreased due to power mismatch and a new steady state point will be reached due to the droop control. Despite the implemented changes, the grid voltage has remained at its rated value.

\section{CONCLUSIONS}

The paper discusses the possibility of implementation of the syncrhonverter concept in a small-scaled microgrid. In this grid, the synchronous machine is absent and the inverter was used to replace it by means of operation as the synchronverter while other less powerful inverters can be connected to such grid.

The functionality of VSG by providing load dependent frequency and voltage were verified. As a result, the other inverters could be involved in the same voltage and frequency regulation.

It is shown that the concept of the synchronverter, which means frequency and peak voltage setting, is not difficult to implement. The qZS network, which is reasonable due to the extended voltage regulation along with improved reliability defines the dynamic behaviour of the inverter.

At the same time, the most complex part consists in the reference power generation. It depends on many factors.

The output voltage control as well as harmonic compensation of the current control of the syncroinverter defines the quality of the output voltage in steady state mode. At the same time, internal microinverter control systems mostly define the quality of the transient process during its connection/disconnection.

\section{REFERENCES}

[1] "Renewables 2016 Global Status Report”, Renewable Energy Policy Network for the $21^{\text {st }}$ Century, Paris, France, March 2016.

[2] Q.-C. Zhong, G.Weiss, "Static synchronous generators for distributed generation and renewable energy", in Proc. Power Syst. Conf. Expo. (PSCE), 2009, pp. 1-6. DOI: 10.1109/PSCE.2009.4840013.

[3] Q.-C. Zhong, G. Weiss, "Synchronverters: Inverters that mimic synchronous generators", IEEE Trans. Ind. Electron, vol. 58, no. 4, pp. 1259-1267, 2011. DOI: 10.1109/TIE.2010.2048839.

[4] Q.-C. Zhong, P.-L. Nguyen, Z. Ma, W. Sheng, "Self-synchronised synchronverters: Inverters without a dedicated synchronisation unit", IEEE Trans. Power Electron, vol. 29, no. 2, pp. 617-630, 2014. DOI: 10.1109/TPEL.2013.2258684.

[5] J. K. Reed, Q. C. Zhong, J. Saniie, "Digital synchronverter design flow for renewable energy", IEEE Int. Conf. Electro Information Technology (EIT 2017), Lincoln, NE, 2017, pp. 363-366. DOI: 10.1109/EIT.2017.8053387.

[6] C. H. Zhang et al., "An improved synchronverter model and its dynamic behaviour comparison with synchronous generator", 2nd IET Renewable Power Generation Conference (RPG 2013), Beijing, China, 2013, pp. 1-4. DOI: 10.1049/cp.2013.1879.

[7] H. Li et al., "Single-phase synchronverter dynamic optimization and parameters design", 43rd Annual Conf. IEEE Industrial Electronics
Society (IECON 2017), Beijing, China, 2017, pp. 7866-7871. DOI: 10.1109/IECON.2017.8217378.

[8] S. Mishra, D. Pullaguram, S. Achary Buragappu, D. Ramasubramanian, "Single-phase synchronverter for a gridconnected roof top photovoltaic system", IET Renewable Power Generation, vol. 10, no. 8, pp. 1187-1194, 2016. DOI: 10.1049/ietrpg.2015.0224.

[9] H. Li et al., "Single-phase synchronverter dynamic optimization and parameters design", 43rd Annual Conf. IEEE Industrial Electronics Society (IECON 2017), Beijing, China, 2017, pp. 7866-7871. DOI: 10.1109/IECON.2017.8217378.

[10] J. M. Ramirez, J. C. Rosas-Caro, "Paralleling a synchronverter and a PWM-based converter for supplying a microgrid", IEEE PES Innovative Smart Grid Technologies Conf.- Latin America (ISGT 2017), Quito, Equador, 2017, pp. 1-6. DOI: 10.1109/ISGTLA.2017.8126727.

[11] S. Dong, Y. C. Chen, "A method to directly compute synchronverter parameters for desired dynamic response", IEEE Trans. Energy Conversion, vol. 99, pp. 1-1. DOI: 10.1109/TEC.2017.2771401.

[12] J. K. Reed, Q. C. Zhong, J. Saniie, "Digital synchronverter design flow for renewable energy", IEEE Int. Conf. Electro Information Technology (EIT 2017), Lincoln, NE, 2017, pp. 363-366. DOI: 10.1109/EIT.2017.8053387.

[13] Phi-Long Nguyen, Q. C. Zhong, F. Blaabjerg, J. M. Guerrero, "Synchronverter-based operation of STATCOM to Mimic Synchronous Condensers", 7th IEEE Conference on Industrial Electronics and Applications (ICIEA 2012), Singapore, 2012, pp. 942-947. DOI: 10.1109/ICIEA.2012.6360859.

[14] Fang Zheng Peng, "Z-source inverter", IEEE Trans. Industry Applications, vol. 39, no. 2, pp. 504-510, 2003. DOI: 10.1109/TIA.2003.808920

[15] Yuan Li, J. Anderson, F. Z. Peng, Liu Dichen, "Quasi-Z-source inverter for photovoltaic power generation systems", 24th Annual IEEE Applied Power Electronics Conf. and Exposition (APEC 2009), 2009, pp. 918-924. DOI: 10.1109/APEC.2009.4802772.

[16] I. Roasto, D. Vinnikov, J. Zakis, O. Husev, "New shoot-through control methods for qZSI-based DC/DC Converters", IEEE Trans. Industrial Informatics, vol. 9, no. 2, pp. 640-647, 2013. DOI: 10.1109/TII.2012.2224353.

[17] Ryota Ichikawa, Hirohito Funato, "Single phase utility interface inverter based on digital hysteresis current controller - Operational characteristics both grid-connected mode and islanding mode", 15th Int. Power Electronics and Motion Control Conf. (EPE/PEMC 2012), Novi Sad, Serbia, 2012. DOI: 10.1109/EPEPEMC.2012.6397525.

[18] Thanh-Vu Tran, Tae-Won Chun, Hong-Hee Lee, Heung-Geun Kim, Eui-Cheol Nho, "PLL- based seamless transfer control between gridconnected and islanding modes in grid-connected inverters", IEEE Trans. Power Electronics, vol. 29, no. 10, pp. 5218-5228, 2014. DOI: 10.1109/TPEL.2013.2290059.

[19] F. Harirchi, M. G. Simoes, M. Babakmehr, A. Al-Durra, S. M. Muyeen, "Designing smart inverter with unified controller and smooth transition between grid-connected and islanding modes for microgrid application", IEEE Industry Applications Society Annual Meeting, pp. 1-7, 2015. DOI: 10.1109/IAS.2015.7356800.

[20] Qin Lei, F. Z. Peng, I. J. Balaguer, "Islanding control of DG in microgrids", IEEE 6th Int. Power Electronics and Motion Control Conf., pp. 450-455, 2009. DOI: 10.1109/IPEMC.2009.5157430.

[21] T. Rudnicki, A. Sikora, R. Czerwinski, D. Polok, "Impact of PWM Control Frequency onto Efficiency of a $1 \mathrm{~kW}$ Permanent Magnet Synchronous Motor", vol. 22, no. 6, pp. 10-16, 2016. DOI: 10.5755/j01.eie.22.6.17216.

[22] J. Anderson, F. Z. Peng, "Four quasi-Z-Source inverters", IEEE Power Electronics Specialists Conf., Rhodes, 2008, pp. 2743-2749. DOI: 10.1109/PESC.2008.4592360.

[23] H. Li, X. Zhang, T. Shao, T. Q. Zheng, "Study on the inertia optimization of grid-friendly single-phase synchronverter", IEEE Energy Conversion Congress and Exposition (ECCE 2017), Cincinnati, OH, 2017, pp. 2934-2939. DOI: 10.1109/ECCE.2017.8096541. 